\title{
Nace «Soy de la Cuesta», asociación ciudadana al rescate de la Feria de Libros de la Cuesta de Moyano de Madrid
}

\author{
LARA SÁNCHEZ \\ Presidenta Asociación Soy de la Cuesta
}

Hace dos años Laura recogió por última vez el tablero y todos los libros de su caseta en la Feria de Libros de la Cuesta de Moyano. Aquella fue una ceremonia triste en una mañana colorida de verano. Ella era una de las primeras libreras por cuenta propia -antes las libreras solo existían como esposas de libreros - que, en su madurez, había apostado por la vocación ansiada, la de ser librera de viejo y ocasión en esa Cuesta hacia El Retiro, donde Baroja aún acompaña, con boina pétrea y mirada perspicaz, a vendedores de ediciones preciosas o baratas, únicas o clásicas y - tras cuarenta años de censura - hasta liberadas; en esa Feria ya centenaria de guardianes de lo imposible y lo olvidado.

A Laura la apuesta le había costado cara, unos 18.000 euros anuales de canon municipal, además de gastos fiscales y de mantenimiento. Era la puja en unos tiempos distintos, cuando vivían bibliófilos a porrón - "la bibliomanía, esa enfermedad incurable", solía decir Don Pío - que aún poblaban, junto a lectores ávidos sin mucho presupuesto, las casetas de Moyano. Gallardón, Siza y Hernández de León aún no habían peatonalizado la Cuesta y los compradores podían meter en los capós de sus coches o taxis un "botín" - término con que otro célebre defensor de Moyano, Arturo Pérez-Reverte, describe el placer de sus compras a libreros - a veces tan nutriente para el intelecto, como imposible de cargar. Entonces tampoco existía Amazon con su diabólico algoritmo para aislarnos del exterior, sustituyendo la recomendación del librero, quien, de corazón y con más memoria que un microchip chino, acierta revelando descubrimientos a los asiduos y visitantes de "la calle más leída de Madrid", según la sentía el gran Paco Umbral.

Nuestra devota librera atendió durante años su caseta con una cara radiante de luz y su peinado corto de precioso blanco natural, hasta que su cuerpo enjuto no pudo contrarrestar los efectos de tanto desacierto municipal contra un negocio que hoy necesita extraordinarios esfuerzos y refuerzos. Hace unos cuatro años el Ayuntamiento de Madrid, en plenas negociaciones para homogeneizar un canon simbólico para todos los libreros - petición recurrente de los mismos -, cesó "por error administrativo" de cobrar sus recibos, para luego golpear, de modo retroactivo y sin perdón, con una tasa acumulada en casos como el de Laura cercana a las seis cifras.

A casi ninguno le salen las cuentas. Hoy los libreros más jóvenes batallan con horas de trabajo ni siquiera cerrando para comer -, llueva, nieve o azote el sol y sin toldos externos que los protejan, por un jornal, en ocasiones, de veinte euros en un día; otros han pedido préstamos bancarios por mero romanticismo hacia su caseta. Laura echó el cierre, admitiendo no tener fuerzas. La suya era la cuarta de esas capillas del placer intelectual extinguida sine die, ante una deleznable desidia municipal y, si me apuran, hasta nacional, porque Moyano es más que un patrimonio ya centenario de nuestra urbanidad castiza, lo es cultural e histórico de España y hasta donde llegue Cervantes.

Bajo el principio de que el acceso abierto a los resultados de investigación acelera el avance del conocimiento, todos los contenidos de la edición electrónica de CLIP se distribuyen bajo una licencia de uso y distribución Creative Commons Reconocimiento-NoComercialCompartirlgual 3.0 España (CC BY-NC-SA 3.0 ES). 


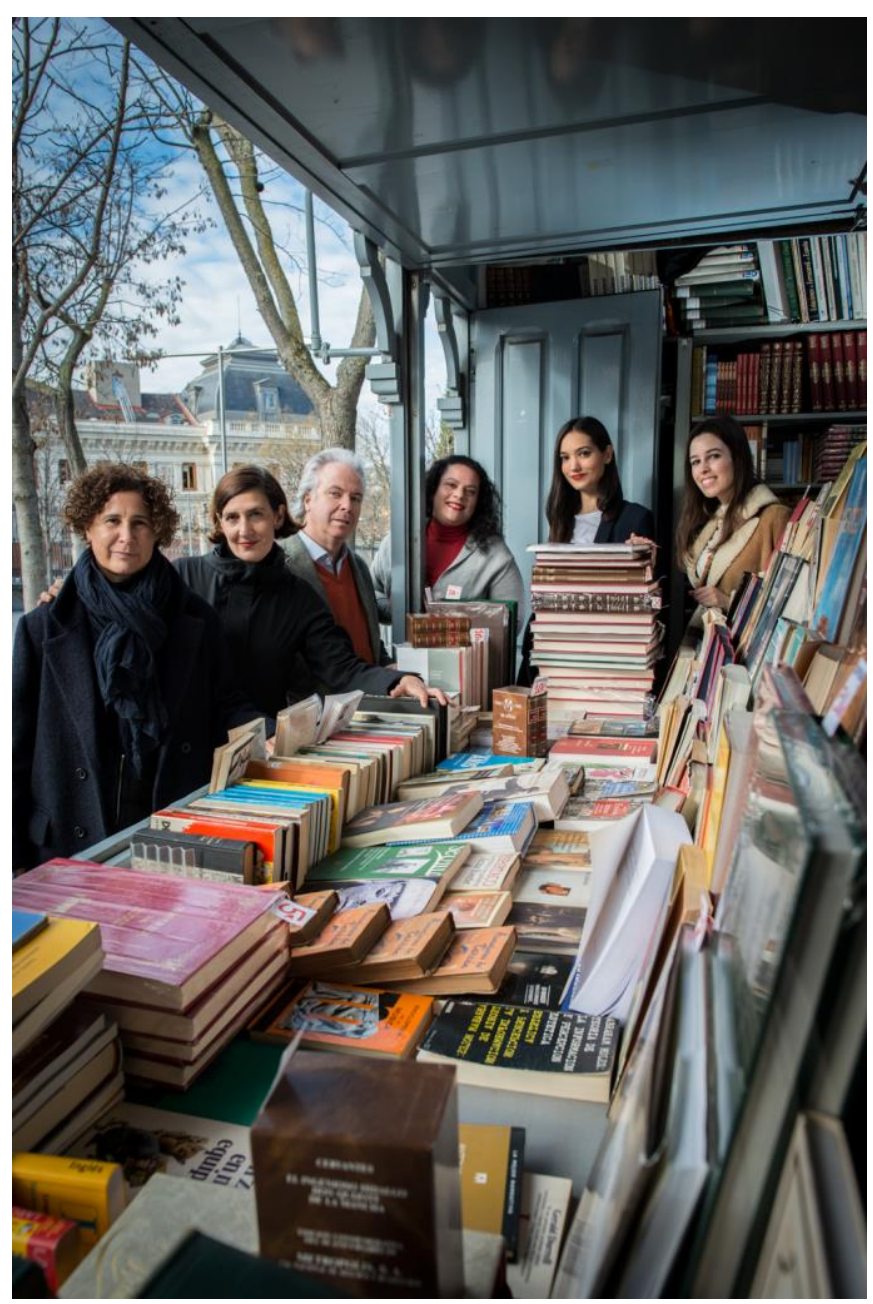

Junta Directiva de la Asociación (Foto: Cris Robles)

Mi abuelo Berchi tenía la caseta número 26. Librero desde niño y en la posguerra, amaba más que a si mismo los libros; quizás porque gracias a ellos creció en un viaje de conocimiento y libertad hasta su final. Surtía gracias a ese amor y su memoria portentosa a clientes, entre los que conocí a políticos, escritores, artistas, militares y académicos. En su puesto a veces coincidían los más dispares - ¿puede Amazon lograr esto? - y se daban tertulias increíbles, mientras yo jugaba a saltar la goma, atada entre el tronco de uno de los árboles de la Cuesta - también los han sustituido por hormigón ardiente - y su tablero, que recuerdo repleto de La Codorniz, Blancos y Negros, La Ilustración, National Geographics y novelas imprescindibles a 200 pesetas.

También recuerdo los domingos de gentío, ejerciendo una coreografía, sin ensayo, pero coordinada, cuesta arriba o hacia abajo, para volcarse sobre esos tableros y fijar iris durante largos ratos sobre estantes de encuadernaciones en piel, primeras del 27, Historias de La Fuente, La Moda, catálogos descatalogados, los Episodios Nacionales, los Australes de colores, las biografías más controvertidas, cómics antiguos, los Crisolines, etc. Siempre he tenido la sensación que en la Cuesta de Moyano a todo tipo de gente se le diera bien parar el tiempo; parecía como si mirar libros allí otorgara un súper poder divino.

No solo el tiempo se ha derramado en Moyano, también es el único lugar de España, y uno de los pocos en Europa, donde continuamente han desembocado tesoros infinitos. Uno de los más preciados de mi abuelo eran unas cartas de Ortega y Gasset a Ramiro de Maeztu - supuestos enemigos ideológicos 
- que logré acabaran en la Biblioteca Nacional. Con el dinero obtenido de su venta financié la campaña 'Soy de la Cuesta', que contó con la colaboración para una serie de vídeos de ilustres amantes de la Feria como Pérez-Reverte, Javier Rioyo, Carmen Iglesias, Antonio Lucas o Pío Caro-Baroja.

Aprovechando el recuerdo a la emancipación de los libreros del bazar de verduras y flores de Atocha en 1919, instaurándose como primera Feria de Libros de Madrid, predicamos las virtudes de Moyano - "porque un libro siempre es nuevo", que decía Peman - en redes sociales, consiguiendo una espléndida respuesta mediática e innumerables mensajes de cariño ciudadano.

Hace solo unos meses emitimos un audiovisual final en el que los famosos defensores de Moyano respondían a la pregunta "¿Qué ocurriría si desapareciera?". Con ello llamamos a la movilización ciudadana para la constitución de la Asociación de amigos de la Feria de Libros de Moyano 'Soy de la

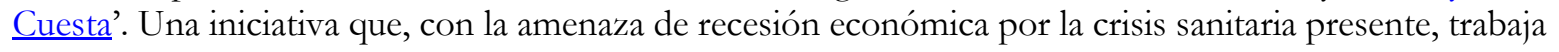
hoy en objetivos muy concretos al rescate de la Feria. Si antes los libreros, sus artífices primordiales, ya rozaban peligrosamente la decadencia o, en el caso de Ángela, la extinción, con este parón mundial se convertirán en víctimas de un puntapié definitivo.

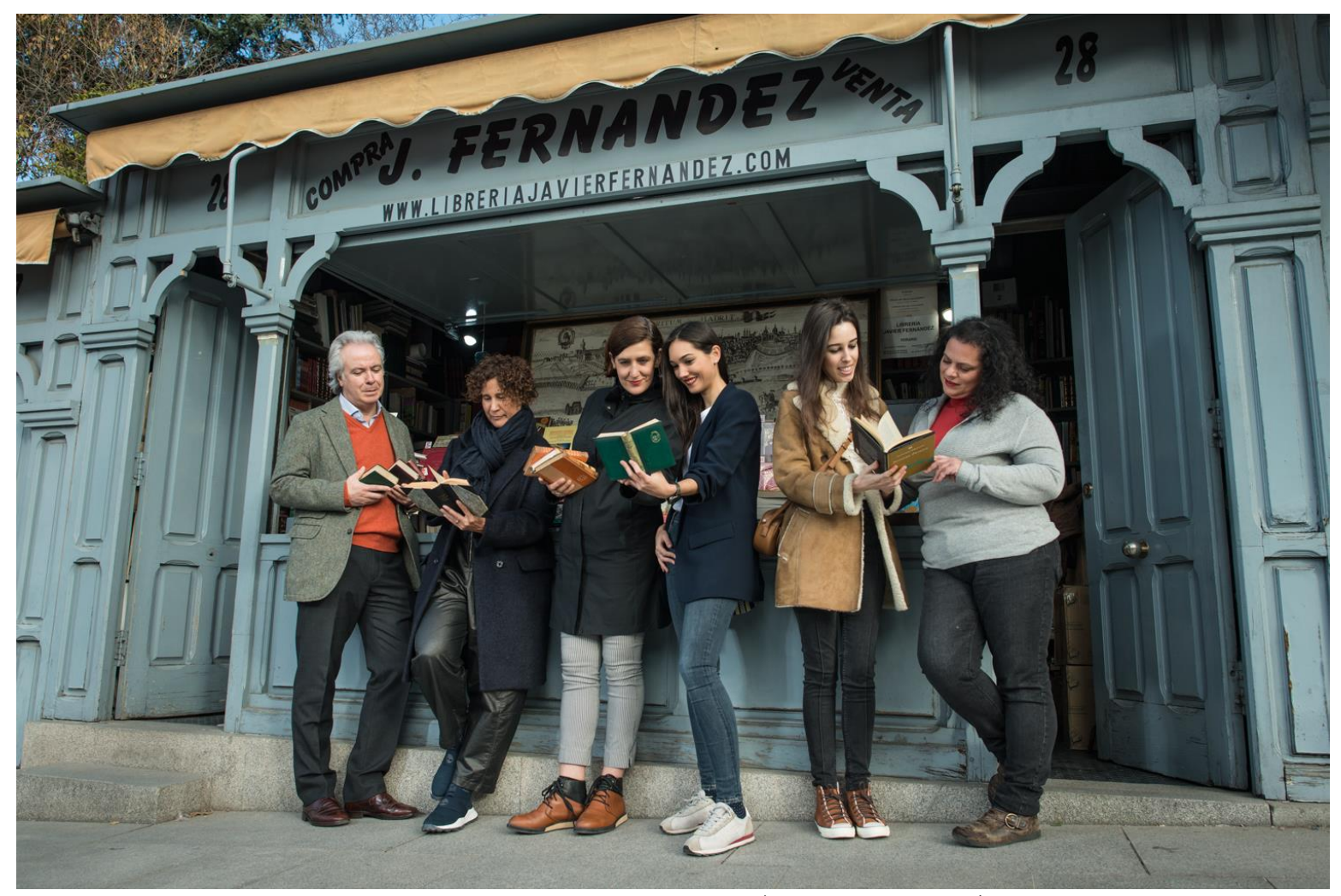

Junta Directiva de la Asociación (Foto: Cris Robles)

Nadie es capaz de imaginar la capital de este país sin una Cuesta de Moyano, pero para eso es indispensable atraer viejos y, sobre todo, nuevos públicos. Por ello, la Asociación, que tiene como socios de honor a todos los célebres representantes de la cultura que ya participaron en la campaña inicial, tiene varios fines: planificar y organizar proyectos y actividades siempre vinculantes a Moyano, difundir su valor histórico, social y cultural entre todos; ejercer la interlocución con las instituciones responsables de su mejora, y convertir el mítico paseo librero en espacio cultural de referencia y futuro. Soñamos con que los hijos y los nietos de los libreros de hoy, junto a nuevos amantes del libro, celebren durante 2120, en pleno reino de la Inteligencia artificial, el segundo centenario de esa Feria de Libros en la Cuesta de Moyano. 
Para su consecución, nada mejor que contar con el apoyo y mimo de sus propios conocedores y valedores, su público, e incluso con cualquier ciudadano que estime importante la supervivencia de comercios artesanales y locales. Por ello, os invitamos a participar en la recuperación de la Cuesta de Moyano, bien visitándola con frecuencia, en cuanto concluya el confinamiento comercial, y llevando de la mano a vuestros hijos, sobrinos y nietos, o muy especialmente, convirtiéndose en socio de Soy de la Cuesta, escribiendo un email que contenga dos líneas con tus razones para salvar Moyano, junto a nombre, apellidos y fecha de nacimiento a cuestamoyano@gmail.com.

\section{Sobre la autora}

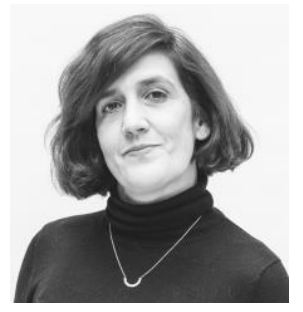

LARA SÁNCHEZ

Presidenta. Asociación Soy de la Cuesta 